\title{
Relation between MR ratio and Nanocrystalline Structure of CPP-GMR Film with a Current-Confined-Path Nano-Oxide Layer
}

\author{
H. Yuasa, H. Fukuzawa, and H. Iwasaki \\ Corporate R \& D Center, Toshiba corp., 1 Komukai-toshiba-cho, Saiwai-ku, Kawasaki 212-8582, Japan
}

\begin{abstract}
Current-Perpendicular-to-Plane Giant MagnetoResistance (CPP-GMR) spin valves with a Current-Confined-Path (CCP) Nano-Oxide Layer (NOL) were investigated from the viewpoint of the relation between MR ratio and nanostructure. We have reported that the CPP-GMR spin valves with the CCP-NOL fabricated by Ion-Assisted Oxidation (IAO) show higher MR ratio than those fabricated by Natural Oxidation (NO). In this report, the nanostructures of CPP-GMR spin valves are compared by means of the high-resolution Transmission Electron Microscope (TEM) and the Fast Fourier Transform (FFT) map. It was confirmed that IAO is effective for improving the crystalline structure not only for the CCP, but also for the free layer on the CCP. The well crystalline structure can decrease the resistivity of the metal path and enhance the spin-dependent scattering inside the free layer, which are considered to be the reasons for the enhancement of MR ratio for the IAO.
\end{abstract}

Key words: CCP-GMR, Spin valve, Current-confined-path (CCP), Nano-Oxide-Layer (NOL), TEM

\section{CCP-NOL を有する CPP-GMR 膜の MR 变化率とナノ微細構造の関係}

\author{
湯浅裕美・福澤英明・岩崎仁志
}

（株）東芝＼cjkstart研究開発センター，川崎市幸区小向東芝町 1（†212-8582）

\section{1.はじめに}

Current-Perpendicular-to-plane Giant-magnetoresistance (CPP-GMR)効果を用いた CPP-GMR 膜は，低抵抗であるというメ リットがあるため将来のハードディスク再生ヘッド有力技術と目 され，開発が進められている. しかしながら CPP-GMR 膜のデメ リットとして MR 変化率が未だ低いことがあり，それを改善する ための磁性層の工夫として, スピン依存散乱の高(材料 ${ }^{1)-8)}$, ホイ

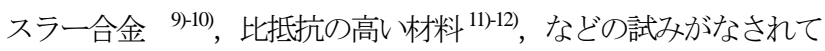
いる. これらにより, Current-in-plane (CIP) -GMRヘッドで用い ていた材料である $\mathrm{CO}_{90} \mathrm{Fe}_{10}$ 合金に比べて $\mathrm{MR}$ 変化率の改善は見ら れたが，まだ不足しているのが現状である.

一方, MR 変化率を増加させるためのスペーサ層の工夫とし て, 電流狭窄型の CPP-GMR 膜が精力的に研究されている. これ は, CPP-GMR 膜のスペーサ層に, 電流を狭窄するための Current-Confined-Path (CCP) Nano-Oxide-Layer (NOL)を用いて MR

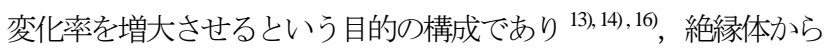
成る NOL に，ピン層とフリー層を接続する CCP を配置したスペ 一サ層である. 様々な材料系が検討され ${ }^{15-23)}$, Conductive atomic force microscopy (AFM) を用いた観察によって, CCP-NOL の形態 が作製方法に依存することが報告されている ${ }^{24)}$. 我々は絶縁部に $\mathrm{Al}_{2} \mathrm{O}_{3}, \mathrm{CCP}$ 部分にCuを用いた系でMR 変化率の向上を確認し ${ }^{16-18),}$

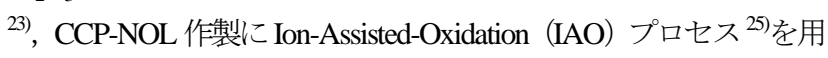
いると自然酸化 (natural oxidation: NO) に対して MR 変化率が 4 倍 に増加すること, この MR 変化率の増加は主にCCP の比抵抗の低 下によるものであることを, 2 電流モデルを用いたフィッティング によって説明した ${ }^{16)}$.

本報告ではNOと IAOの違いをナノ微細構造の観点から明らか にすることを目的として, 高分解能透過型電子顕微鏡（high resolution transmission-electron-microscope: TEM) によって CPP-GMR 膜の断面構造を観察し, 更に画像を高速フーリエ変換 (Fast Fourier
Transform : FFT） した結果をマッピングした像 ${ }^{26) て ゙ ， C C P ~ お よ ひ ゙ ~}$ CPP-GMR 膜の結晶性を比較した. FFT のマッピング像には, 局所 的な結晶配向性を分布として把握できるという長所がある. この 手法を用いて, MR 変化率と CCP-NOL 近傍のナノ微細構造との相 関について調べた.

\section{CPP-GMR 膜の MR 特性とナノ微細構造観察方法}

CCP-NOL を有する CPP-GMR 膜の膜構成は, Ta 5/Ru 2/PtMn 15/ $\mathrm{Co}_{90} \mathrm{Fe}_{10}$ 4/Ru 9/Co ${ }_{90} \mathrm{Fe}_{10}$ 4/CCP-NOL 1.5/Cogo $\mathrm{Fe}_{10}$ 1/NiFe 3.5/cap

(数字は膜厚 $[\mathrm{nm}]$ ) である. 模式四を Fig. 1 に示す. CCP-NOL は 自然酸化 (NO) と Ion-Assisted-Oxidation (IAO) の 2 通りで作製し, 成膜後に $270^{\circ} \mathrm{C} て ゙ 10$ 時間アニールした. このような CPP-GMR 膜 の MR 変化率は, 素子によって確認されており, Fig. 2 に示すよう にIAO で形成した場合はNO で形成した場合よりも4倍の MR 変 化率を示寸ことが分かっている ${ }^{16)}$. このような MR 変化率の違い

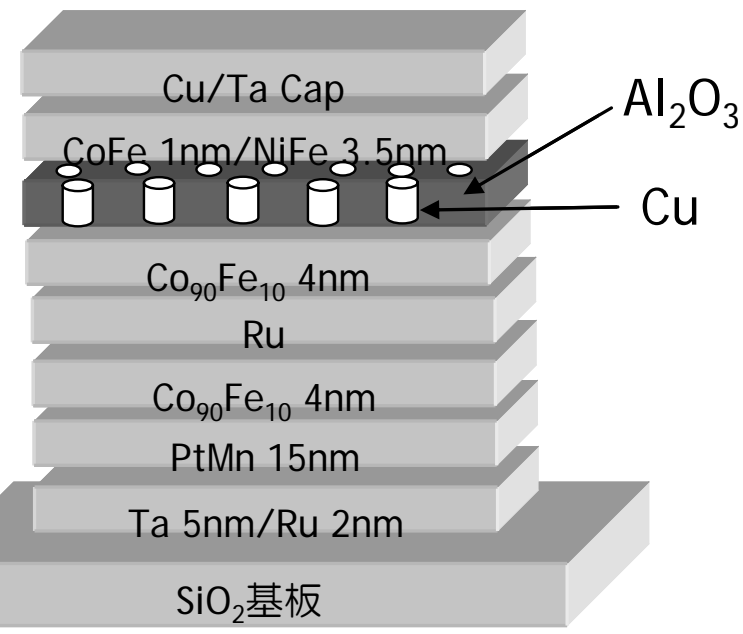

Fig. 1 Schematic image of the spin valve with CCP-NOL. 


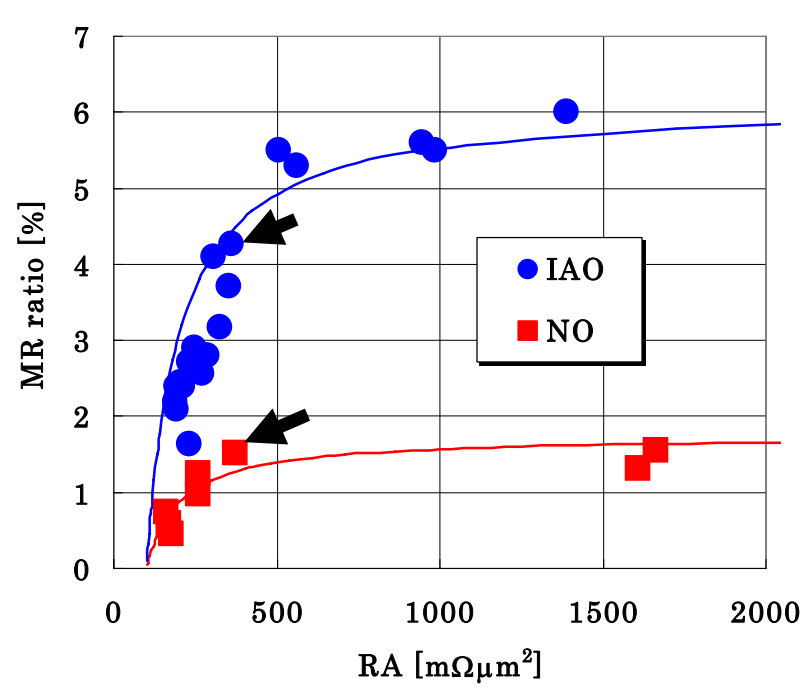

Fig. 2 MR ratio dependence on $R A$ of the spin valves with the CCP-NOL. The red square and blue circle denote the MR ratio of the spin valves with the CCP-NOL fabricated by NO and IAO process, respectively. ${ }^{16)}$

を示した二つの構成について断面 TEM 観察を行った. ここで, 観 察を行った膜は，Fig. 2 に矢印で示したように，NO，IAO ともに $R A$ が約 $350 \mathrm{~m} \Omega \mu \mathrm{m}^{2}$ とほぼ同じ值を示したサンプルである.

これらの試料の断面構造を高分解能 TEM によって観察し, 更に FFT を施した. FFT 処理をすると, 電子線回折で得られる情報, すなわち格子面閒隔や配向面方位が得られる. 電子線回折に対す るメリットとして，取り込む視野を選択できること，および得ら れた情報を断面 TEM 像と同じ視野で連続的にマッピングして表 示できることがある.このため, $1 \mathrm{~nm}$ オーダーの局所的な結晶配 向性の分布を, $100 \mathrm{~nm}$ オーダーの視野において一括に把握するこ とができる. 今回行った FFT では $1[\mathrm{~nm}] \times 1[\mathrm{~nm}] の$ 面積において, その画像の周期性からフーリエ変換した. したがって, FFT 像の 空間分解能は約 $1 \mathrm{~nm}$ である.

\section{3. ナノ微細構造観察結果}

CCP-NOL を有する CPP-GMR 膜の断面 TEM 実像を Fig. 3 に示 す. NO による断面 TEM 像が Fig. 3(a)，IAO によるものが Fig. 3(b) である. 図の中の白い線状のものがCCP-NOL であり, 白い四角で 囲んだ部分にCCP を観測することができた. CCP を詳細に比較す るため, Fig. 3(a)と Fig. 3(b)において左側に観測された CCP(1)と CCP(2)を拡大して, Fig. 3(c)と Fig. 3(d)にそれぞれ示した. 注目す べき点として, NO と IAO でCCP の結晶性が大きく異なることが わかった. Fig. 3(c)に示した NOによるCCP では良好な結晶性を示 す領域を見つけることができないのに対し, Fig.3(d)のIAOによる CCP-NOL では CCP に結晶格子を明確に認めることができる. こ れにより, CCP の結晶性が，IAO プロセスによって改善されてい ることが断面 TEM 実像から明らかになった.

次に, ナノ微細構造をより詳細に解析するために, Fig. 3 に示し た断面 TEM 実像に対して FFT を実施した. FFT により得られた
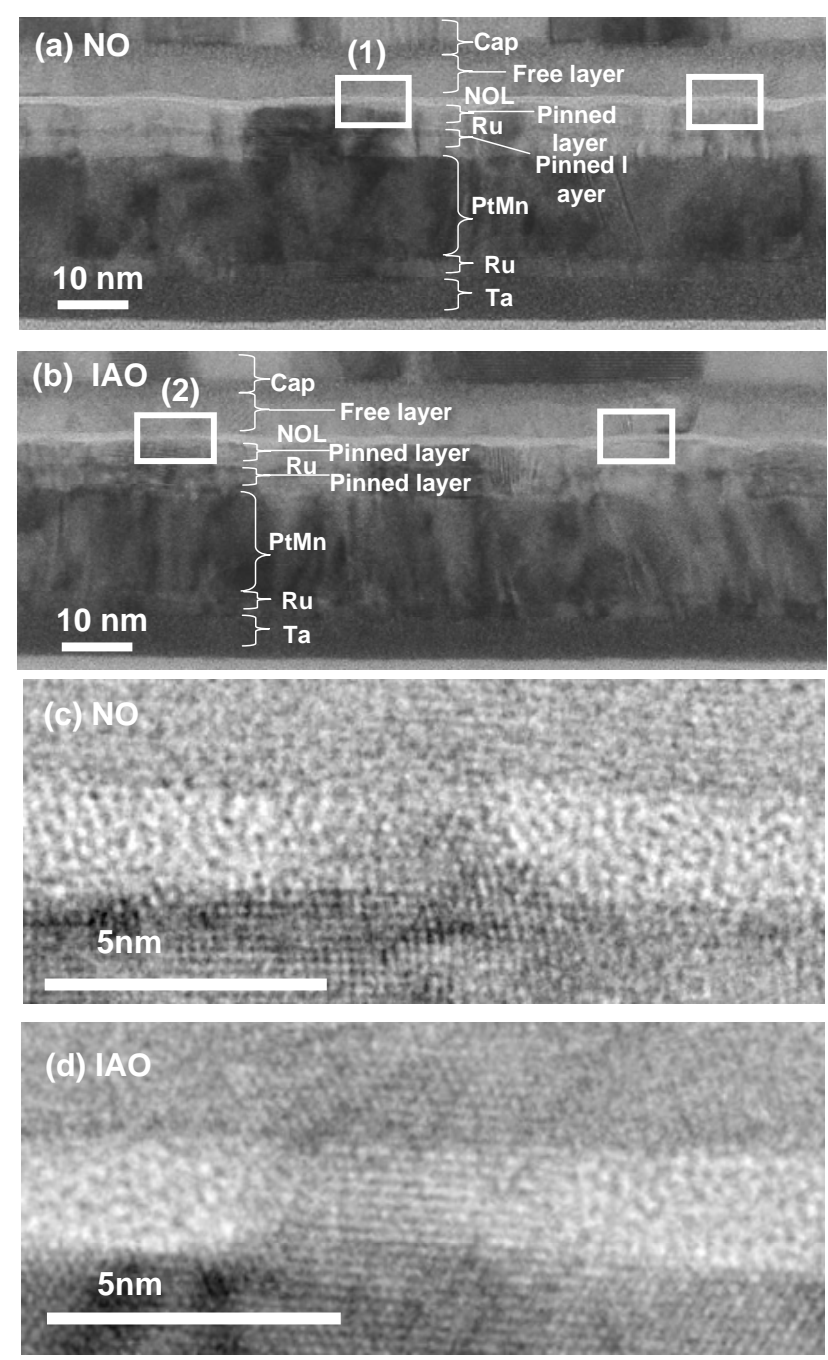

Fig. 3 Cross-sectional high-resolution TEM images of the spin valves with CCP-NOL fabricated by NO (a) and IAO (b). CCP regions (1) and (2) are enlarged in (c) and (d), respectively.

格子面間隔をマッピングした FFT 像を Fig. 4 に示す. Fig. 3(a)を変 換したものが Fig. 4(a), Fig. 3(b)を変換したものが Fig. 4(b)である. FFT 像は格子面間䛿が $1.9 \AA$ の赤色から $2.3 \AA$ の紫色まで, 連続的 に変化した色で表される. ここで, 周期性が不足してフーリエ変 換できなかった部分は，黒く表示される.

FFT 像を見ると, いずれの CPP-GMR 膜もピン層の結晶は格子 面間䛿約 $2.01 \AA$ できれいに配向しているのに対し, フリー層では 原子配列が明瞭ではないことが分かる. フリー層はアモルファス の $\mathrm{Al}_{2} \mathrm{O}_{3}$ 上に成長しているため, ピン層からの結晶成長が途絶えて 微結晶となっているためである. これはフーリエ変換前の断面 TEM 実像からも判別できることではあるが, FFT を用いることで より直感的に識別することができた.

さらに詳細に見ると, Fig.4(b)のIAO の場合には, フリー層であ っても白い丸で囲んだ部分においては結晶性が良好である. Fig. 3(b)との比較により, 結晶性が良好な部分は CCP の上に成長した フリー層であることがわかった. これは, CCP の良好な結晶配向 性が, フリー層まで連続しているためである. それに対し, Fig.4(a) 

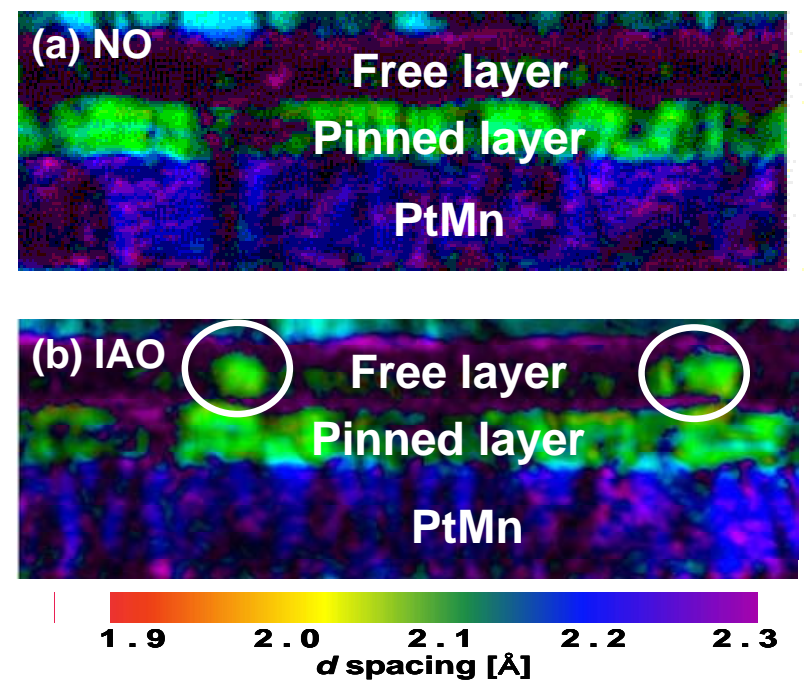

Fig. 4 FFT images of the spin valves with CCP-NOL fabricated by NO (a) and IAO (b), respectively.

の NO の場合には，フリー層中に良好な結晶配向を示す領域を全 く認めることができない. したがって, CCP-NOL をIAO によっ て形成することで, CCP，ならびにその上に膜成長するフリー層 の結晶配向性を極めて良い状態で形成できることがわかった。

\section{4. 議論}

CCP-NOL 近傍のナノ微細構造の違いと MR 変化率との 相関について議論する。これまで, CCP-NOL 作製方法を NOから IAO に変えることでMR変化率が向上する主因は, CCP の比抵抗が下がるためであることを， 2 電流モデルに よるフィッティングから考察していた ${ }^{16)}$. 本報告ではナノ 微細構造観察により, IAO を用いることで CCP の結晶性が 向上することを確認した。一般的に金属の結晶性が向上す ることで比抵抗は低減する。このことから, CCP-NOL 作製 方法を NOから IAO に変えることでCCPの結晶性が向上し て、2 電流モデルによるフィッティングから考察されてい た比抵抗の低減が実現され，MR 変化率が向上することを 実験的に検証することができた.

さらに, IAO によって結晶性が改善した CCP 直上のフリ 一層では伝導電子の非弾性散乱が減少し, スピン依存バル ク散乱が改善することが推察される。つまり, CCP-NOL 作 製プロセスを NO から IAO に変えることで, MR 変化率向 上を説明したモデルでは無視していたスピン依存バルク散 乱効果も上昇しているものと考えられる.

以上のことから, 結晶性の改善により 2 電流モデルによ るフィッティングから示されていたCCPの比抵抗低減が実 現し, さらにフリー層のスピン依存バルク散乱効果上昇し, MR 変化率が増加したと考えられる. したがって, 結晶配 向性の良好な CCP をいかに形成するかが, 高 MR 変化率を 実現するためのキーポイントであることがわかった.

次に, CPP-GMR 膜の結晶成長モデルについて考察する. Fig. 5 はモデルを説明するための模式戝である. Fig. 5(a)に示したNOの (a) NO

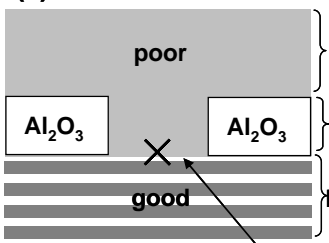

Crystalline growth is broken. (b) IAO

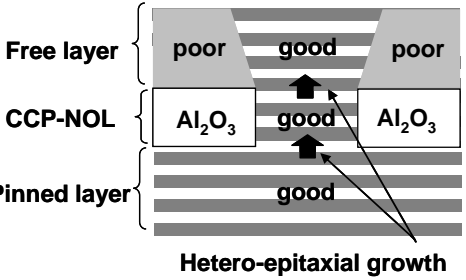

Fig. 5 Crystalline growth model of the spin valves with the CCP-NOL fabricated by NO (a) and IAO (b), respectively.

場合には, ピン層までは通常の金属 CPP-GMR 膜と同様に膜面垂 直に連続成長して配向しているが, CCP-NOL は概ねアモルファス の $\mathrm{Al}_{2} \mathrm{O}_{3}$ から成るので, 連続的な結晶成長が途絶える. CCP は金 属 $\mathrm{Cu}$ であるが，Fig. 3(a)から分かるように配向性が非常に悪いの でCCP において連続成長が止まり, その結果フリー層は一様に微 結晶となる. これに対し, Fig. 5(b)のIAOの場合には, スペーサ層 のCCP が良好な結晶性で形成され，その良好な結晶配向性がフリ 一層まで㰅続した, エピタキシャル成長となっている. 断面 TEM 実像と FFT 像から, CCP-NOL をIAO で作製することで, CCP の 結晶配向性を向上するだけでなく，その上のフリー層においても 良好な結晶配向性が得られるという結晶成長モデルで, CPP-GMR 膜のナノ微細構造を説明することができた.

ここで, IAO による結晶性 CCP の形成メカニズムについ て考察する. IAO においては, 酸化過程において Arイオン ビームを照射する，一方で，成膜時に照射されるイオンビ 一ムがそのエネルギーによって薄膜の結晶化を促進するこ とが報告されている ${ }^{27)}$. 本報告における IAO では酸化時に イオンビームを照射しているが，酸化薄膜形成過程におい てもCCPの結晶化を促進させる効果が得られたものと考え られる。

\section{5. 結論}

NO とIAO によって作製した CCP-NOL を持つ CPP-GMR 膜のナノ微細構造を観察し, MR 変化率とナノ微細構造の 相関を調べた．IAO で形成することで，CCP の結晶配向性 が向上することがわかった. 結晶性の向上により CCP の比 抵抗が低減すると考えられ，CCP の抵抗が低減することで $\mathrm{MR}$ 変化率が向上すると説明した 2 電流モデルを裏付けた. さらに IAO によって CCP の直上におけるフリー層の結晶 性までも向上寸ることがわかった。これはスピン依存バル ク散乱の向上を示唆するものである.CPP-GMR 膜の微細構 造と MR 変化率の比較により, さらなる高 $\mathrm{MR}$ 変化率を実 現するためには，CCP とフリー層を良好な結晶性で形成す ることが重要であると考えられる.

\section{References}

1) A. C. Reilly, W. -C. Chiang, W. Park, S. Y. Hsu, R. Loloee, S. Steenwyk, W. P. Pratt Jr., and J. Bass : IEEE Trans. Magn. 34, 939 (1998).

2) A. C. Reilly, W. Park, R. Slater, B. Ouaglal, R. Loloee, W. P. 
Pratt Jr., and J. Bass : J. Magn. Magn. Mater. 195, L269 (1999).

3) Q. Yang, P. Holody, R. Loloee, L. L. Henry, W. P. Pratt Jr., P. A. Schroeder, and J. Bass : Phys. Rev. B 51, 3226 (1995).

4) W. P. Pratt Jr., Q. Yang, L. L. Henry, P. Holody, W. -C. Chiang, P. A. Schroeder, and J. Bass : J. Appl. Phys. 79, 5811 (1996).

5) H. Yuasa, M. Yoshikawa, Y. Kamiguchi, K. Koi, H. Iwasaki, M Takagishi and M. Sahashi: J. Appl. Phys. 922646 (2002).

6) H. Yuasa, H. Fukuzawa, H. Iwasaki, M. Yoshikawa M. Takagishi and M. Sahashi: J. Appl. Phys. 937915 (2003).

7) H. Yuasa, H. Fukuzawa and H. Iwasaki: J. Magn. Magn. Matt. 28695 (2005).

8) H. Yuasa, H. Fukuzawa. H. Iwasaki and M. Sahashi: J. Appl. Phys. 97113907 (2005).

9) H. Hoshiya and K. Hoshino: J. Appl. Phys. 956774 (2004).

10) M. Saito, N. Hasegawa, Y. Ide, T. Yamashita, Y. Nishiyama, M. Ishizone, S. Yanagi, K. Honda, N. Ishibashi, D. Aoki, H. Kawanami, K. Nishimura, J. Takahashi and A. Takahashi: Digest of INTERMAG Conference, FB-02 (2005).

11) A. Jogo, K. Nagasaka, T. Ibusuki, Y, Shimizu, A. Tanaka and H. Oshima: J. Magn. Magn. Matt. 30980 (2007).

12) S. Maat, M. J. Carey and J. R. Childress: J. Appl. Phys. 101 093905 (2007).

13) M. Takagishi, K. Koi, M. Yoshikawa, H. Funayama, H. Iwasaki and M. Sahashi: IEEE Trans. Mag. 382277 (2002).

14) H. Fujiwara, T. Zhao, G. Mankey, K. Zhang, W. H. Butler and S. Matsunuma: Trans. Magn. Soc. Jpn., 395 (2004).
15) K. Nagasaka, Y. Seyama, L. Verga, Y. Shimizu and A. Tanaka: J. Appl. Phys. 896943 (2001).

16) H. Fukuzawa, H. Yuasa, S. Hashimoto, K. Koi, H. Iwasaki and M. Takagishi: IEEE Trans. Mag. 402236 (2004).

17) H. Fukuzawa, H. Yuasa, S. Hashimoto, H. Iwasaki and Y. Tanaka: Appl. Phys. Lett. 87, 082507 (2005).

18) H. Fukuzawa, H. Yuasa, K. Koi, H. Iwasaki, Y. Tanaka, Y. K. Takahashi and K. Hono: J. Appl. Phys. 97 10C509 (2005).

19) K. Nakamoto, H. Hoshiya, H. Katada, T. Okada, M. Hatatani, K, Hoshino, N. Yoshida, I. Nunokawa, K. Etoh and K. Watanabe: IEEE Trans. Magn. 41, 2914 (2005).

20) K. Hoshino and H. Hoshiya: J. Appl. Phys. $908 \mathrm{~T} 103$ (2006).

21) K. Hoshino and H. Hoshiya: IEEE Trans. Mag. 422453 (2006).

22) A. Jogo, Y. Seyama, T. Ibusuki, K, Nagasaka, Y. Shimizu, T. Uzumaki and A. Tanaka: IEEE Trans. Mag. 422456 (2006).

23) H. Fukuzawa, H. Yuasa and H. Iwasaki: J. Phys. D.: Appl. Phys. 40, 1213 (2007).

24) S. Kawasaki, S. Su, K. Miyake, M. Doi and M. Sahashi, $J$. Magn. Soc. Jpn., 30, 357 (2006).

25) H. Fukuzawa, K. Koi, H. Tomita, H. N. Fuke, H. Iwasaki and M. Sahashi: J. Appl. Phys. 916684 (2002).

26) T. Ide, A. Sakai and K. Shimizu, Jpn. J. Appl. Phys. 37, L1546 (1998)

27) M. Sasase, I. Takano, S. Shoji and S. Yokoyama, IEEJ Transaction on Fundamentals and Materials, 116, 804 (1996).

2007年10月4日受理，2008年2月14日採録 